\title{
Moving Ideas from Lab to Marketplace: A Guide to Research
}

\author{
Riccardo Fini (University of Bologna, Italy) \\ Einar Rasmussen (Nord University Business School) \\ Johan Wiklund \\ Mike Wright (Imperial College London)
}

KEYWORDS: Research Methods, Technology Commercialization, Discovery.

Many of today's best innovations - the ones that have created powerhouse companies and have transformed industries, regions and society itself - started as a discovery in a lab. Firms that know how to turn a promising discovery into a viable product gain a tremendous competitive advantage.

Science commercialization drives innovation in many industries and localities, and is an important part of innovation and technology management. New scientific inventions and knowledge creation also can impact society [1], and ultimately can contribute to developing a better world. Not surprisingly, more academic researchers are studying how science can be effectively commercialized, emphasizing technologycommercialization activities, university-industry collaborations, and academic entrepreneurship.

We reviewed the leading management journals and identified 40 articles from the past 15 years that used empirical data from science commercialization to advance management research(\#_ftn1). Two major themes emerged. The two themes were: (a) managing the complex, bumpy and time-consuming process of moving from academic to commercial contexts, and (b) issues that arise when the people engaged in science commercialization try to balance different goals amongst stakeholders.

This article highlights key areas that are addressed within each of the two themes. A deeper discussion can be found in our Journal of Management Studies article (https://onlinelibrary.wiley.com/doi/abs/10.1111/joms.12 424? $\mathrm{af}=\mathrm{R} \&$ ) and in the other articles referenced here.

\section{Managing the Transition Between Academic and Commercial Contexts}

Science commercialization involves bridging academia

and business in order to bring knowledge and technology from the research lab to products and services in the marketplace. Managing such a transition is cumbersome and takes time because it requires collaboration between actors that differs in substantial ways. Academics build their careers through contributions to general knowledge that are recognized by the scientific community, such as through publishing novel scientific discoveries. In contrast, commercial success is built on specific applications of knowledge, where intellectual property protection, development speed, and appropriation of value are more important than novelty. Because the academic and the business environments are so different, many factors will influence how the people involved will behave, such as the anticipated coordination costs between academia and business [2], the different use of network ties and relationships [3] and whether research organizations are set up to handle such different tasks simultaneously (ambidexterity) [4].

Research has examined the hurdles of making transitions across the boundary between the academic and the business sector at several levels of analysis. The tensions between academic and commercial demands are found to be more problematic at an individual than at an organizational level [4]. At the individual level, tensions between academic and business environments influence the collaborative behaviors of scientists [4], the strategic decisions of science-commercialization [5,6], as well as the perceptions of other audiences to which scientists turn for resource acquisition and individual legitimation [7]. These tensions can only to some degree be overcome by putting together teams working across the boundary of science and business.

At the organizational-level, research suggests that

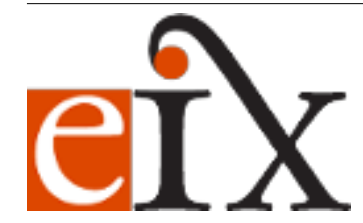

Copyright ( $) 2020$ The Authors. Entrepreneur \& Innovation Exchange is published at EIX.org. This is an open access article under the terms of the Creative Commons Attribution-NoDerivs License, which permits use and distribution in any medium, provided the original work is properly cited and no modifications or adaptations are made. View EIX.org Authorship Terms at https://eix.org/terms 
organizations that can bridge science and commercial logics are better positioned to generate knowledge [3] and enhance business performance [8]. However, the multi-stakeholder and complex nature of the transitioning between science and business [9] are often emphasized. In particular, within-organization resource complementarity [10] and resource dependence [11] have been linked to organizational performance. Further, literature has also studied the ability of organizations to source science-based knowledge from universities and public research institutions [12,13], and how such behaviors resulted in more or less knowledge creation [14] and production of high impact innovations [15].

These studies emphasize the relatively large and distinctive differences between the academic and the business worlds, addressing how individuals and organizations deal with conflicting demands, through, for instance, cognitive and social processes and organizational ambidexterity.

\section{Managing the Variety of Goals and Impacts in Science Commercialization}

Science commercialization encompasses a range of expectations, goals and values held by distinctly different stakeholders, and translating these goals into outcomes generates different impacts. Apart from direct commercial outcomes for participating firms, science commercialization can also impact academic research and teaching, regional and industrial development, and technological and societal change [16].

Such heterogeneity is associated with multiple outcomes and impacts across several levels of analysis. At the individual level, scientists' engagement in commercialization activity, such as academic entrepreneurship, is driven by a multitude of motivations, related to technology diffusion, technology development, financial gain, public service and peer motivations [17]. Individual preferences [18] and goals [19], as well as norms of particular departments and disciplines [20] influence how scientists engage in science commercialization. Also, their scientific backgrounds [21] and social pressures [22] influence science commercialization behaviors, and the quality of individual-and group-level scientific and innovative outcomes [23]. Many individuals involved in science commercialization span organizational and identity boundaries (e.g., university professor vs. entrepreneur in a new venture), making social identity issues particularly challenging in this context [24].

Research has also emphasized how the firms' levels of engagement in technology-licensing behaviors [25], university-industry collaborative efforts $[26,27]$ and scientific-disclosing behaviors [28] have important implications for their ability to create value from science commercialization. By linking organizational goals to impacts in science commercialization, research has addressed the foundations of science-based firms economic performance [29,30] and market value [31], as well as the scientific value of their innovative behaviors [32,33].

Science commercialization represents a context in which multiple impacts may occur. In fact, the recent science commercialization debate is moving beyond maximizing the number of commercialization projects (i.e. spin-offs and licenses) and revenue generated, to a greater emphasis on their broader role of facilitating research and its societal impact. A good example of this development is the U.S. Association of University Technology Managers' "Better World Project," which was launched in 2005 to promote public understanding of how academic research and technology transfer benefits individuals, local communities and mankind.

Studies have also addressed how changes at one level of analysis can lead to changes at another. For instance, they show that science commercialization, in terms of university spin-off firms performing well, can influence the performance of the university in terms of higher research income [34]. Similarly, institutional changes at the university level may alter individuals' beliefs and behaviors [35]. Yet, to generate positive outcomes, such changes need to be consistent with the broader institutional environment to which individuals and firms are exposed.

These studies illustrate the variety of goals exhibited by scientists and how these goals influence their behavior. They also show that individual and institutional characteristics can determine subsequent behavior.

\section{Takeaways for Key Stakeholders}

While the academic literature is generally focused on the themes described above, entrepreneurs and policy makers can glean important insights from this work: 
Intermediary

organizations

are growing. Universities and research organizations are changing, and commercializing science is increasingly important to their missions. These changes are creating hybrid public-private organizations with potentially conflicting objectives between such third mission activities and more traditional university activities [36]. Research institutions have created intermediary organizations that bridge academia and business and encourage knowledge transfer activities [37]. For instance, Technology Transfer Offices, research centers, incubators, accelerators, broker services and co-creation labs involving academic and commercial stakeholders have flourished across the globe over the last decade.

\section{Personal and organizational missions are} changing. Today virtually all research organizations have intermediaries to support the commercialization of science, so science commercialization is increasingly seen as a legitimate activity. These transformations have redesigned the boundaries between public and private science and systematically reshaped the missions of the organizations that engage in it, and in turn the identities and preferences of the people involved. It's not clear how successful universities have been in recruiting individuals with the appropriate networks to link business and academia.

More people are straddling both worlds. The role of scientist-entrepreneurs, whether through start-ups, licensing or patenting, can vary depending on where they work. Scientists may need to work with other universities to get an idea commercialized, and transitions can be unsettling if the old and new organizations share differing goals. [38]. A further issue concerns the potential resistance by incumbents to new, socially beneficial innovations emanating from the lab.

\section{Entrepreneurs and investors must create new ties .}

They must not only identify knowledge that might turn into a commercialized product or service, but also build relationships with academics and universities who will help them make it happen. This means understanding how those researchers, professors and others in academia think and what motivates them. Only then can they understand one another's goals and have the collaboration that drives commercialization.

$\begin{array}{lcr}\text { Schools } & \text { should } & \text { evaluate rewards } \\ \text { systems. Colleges and Universities should evaluate }\end{array}$ how to incentivize and evaluate academic scientists if they desire more commercialization of science. Academic institutions often reward one thing -academic publications -- but also expect and celebrate the commercialization of scientific knowledge. This can create conflict and confusion over goals. Schools should consider designing incentive and evaluation mechanisms that balance these conflicting objectives and accommodate the varying strengths and goals of their research scientists, whether they want to create knowledge or create innovations that can make it in the marketplace. Ultimately, addressing these issues comes down to answering the question: what do we want our university to be?

More research is needed. Science commercialization is gaining more attention as organizations and managers face increasing pressures related to how they can contribute to sustainable development and wellbeing alongside traditional business objectives. This more complex landscape calls for a deeper understanding of how innovations originating from the frontiers of science are exploited and commercialized, and eventually used to solve broader and more complex societal issues.

\section{References}

1. Fini, R., et al., Theories from the Lab: How Research on Science Commercialization can Contribute to Management Studies. Journal of Management Studies, 2019. 56(5): p. 865-894.

2. Kotha, R., G. George, and K. Srikanth, Bridging the Mutual Knowledge Gap: Coordination and the Commercialization of University Science. Academy of Management Journal, 2013. 56(2): p. 498-524.

3. Tortoriello, M. and D. Krackhardt, Activating Cross-Boundary Knowledge: The Role of Simmelian Ties in the Generation of Innovations. Academy of Management Journal, 2010. 53(1): p. 167-181.

4. Ambos, T.C., et al., When Does University Research Get Commercialized? Creating Ambidexterity in Research Institutions. Journal of Management Studies, 2008. 45(8): p. 1424-1447.

5. Chai, S., Near Misses in the Breakthrough Discovery Process. Organization Science, 2017. 28(3): p. 411-428.

6. Nelson, A.J., How to Share "A Really Good 
Secret": Managing Sharing/Secrecy Tensions Around Scientific Knowledge Disclosure. Organization Science, 2016. 27(2): p. 265-285.

7. Fini, R., J. Jourdan, and M. Perkmann, Social valuation across multiple audiences: The interplay between ability and identity judgments. Academy of Management Journal, 2018(In Press).

8. Toole, A.A. and D. Czarnitzki, Exploring the Relationship Between Scientist Human Capital and Firm Performance: The Case of Biomedical Academic Entrepreneurs in the SBIR Program. Management Science, 2009. 55(1): p. 101-114.

9. Ambos, T.C. and J. Birkinshaw, How Do New Ventures Evolve? An Inductive Study of Archetype Changes in Science-Based Ventures. Organization Science, 2010. 21(6): p. 1125-1140.

10. Hess, A.M. and F.T. Rothaermel, When are assets complementary? star scientists, strategic alliances, and innovation in the pharmaceutical industry. Strategic Management Journal, 2011. 32(8): p. 895-909.

11. Kehoe, R.R. and D. Tzabbar, Lighting the way or stealing the shine? An examination of the duality in star scientists' effects on firm innovative performance. Strategic Management Journal, 2015. 36(5): p. 709-727.

12. Sullivan, D.M. and M.R. Marvel, Knowledge Acquisition, Network Reliance, and Early-Stage Technology Venture Outcomes. Journal of Management Studies, 2011. 48(6): $\mathrm{p}$. 1169-1193.

13. Perkmann, M., M. McKelvey, and N. Phillips, Protecting Scientists from Gordon Gekko: How Organizations Use Hybrid Spaces to Engage with Multiple Institutional Logics. Organization Science, 2018. In Press.

14. West, J., Commercializing Open Science: Deep Space Communications as the Lead Market for Shannon Theory, 1960-73. Journal of Management Studies, 2008. 45(8): p. 1506-1532.

15. Gittelman, M. and B. Kogut, Does Good Science Lead to Valuable Knowledge? Biotechnology Firms and the Evolutionary Logic of Citation Patterns. Management Science, 2003. 49(4): p. 366-382.

16. Fini, R., et al., Rethinking the Commercialization of Public Science: From Entrepreneurial Outcomes to Societal Impacts. The Academy of
Management Perspectives, 2018. 32(1): $p$. 4-20.

17. Lam, A., What motivates academic scientists to engage in research commercialization: 'Gold', 'ribbon' or 'puzzle'? Research Policy, 2011. 40(10): p. 1354-1368.

18. Roach, M. and H. Sauermann, Founder or Joiner? The Role of Preferences and Context in Shaping Different Entrepreneurial Interests. Management Science, 2015. 61(9): $p$. 2160-2184.

19. Bercovitz, J.E.L. and B.B. Tyler, Who I Am and How I Contract: The Effect of Contractors' Roles on the Evolution of Contract Structure in University-Industry Research Agreements. Organization Science, 2014. 25(6): p. 1840-1859.

20. Rasmussen, E., S. Mosey, and M. Wright, The influence of university departments on the evolution of entrepreneurial competencies in spin-off ventures. Research Policy, 2014. 43(1): p. 92-106.

21. Gruber, M., D. Harhoff, and K. Hoisl, Knowledge Recombination Across Technological Boundaries: Scientists vs. Engineers. Management Science, 2013. 59(4): p. 837-851.

22. Bercovitz, J. and M. Feldman, Academic Entrepreneurs: Organizational Change at the Individual Level. Organization Science, 2008. 19(1): p. 69-89.

23. Bikard, M., F. Murray, and J.S. Gans, Exploring Trade-offs in the Organization of Scientific Work: Collaboration and Scientific Reward. Management Science, 2015. 61(7): p. 1473-1495.

24. Tajfel, H., Social identity and intergroup relations. 2010: Cambridge University Press.

25. Ziedonis, A.A., Real Options in Technology Licensing. Management Science, 2007. 53(10): p. 1618-1633.

26. Lacetera, N., Different Missions and Commitment Power in R\&D Organizations: Theory and Evidence on Industry-University Alliances. Organization Science, 2009. 20(3): p. 565-582.

27. Mindruta, D., Value creation in university-firm research collaborations: A matching approach. Strategic Management Journal, 2013. 34(6): p. 644-665.

28. Polidoro, F. and M. Theeke, Getting Competition Down to a Science: The Effects of 
Technological Competition on Firms' Scientific Publications. Organization Science, 2012. 23 (4): p. 1135-1153.

29. Lowe, R.A. and A.A. Ziedonis, Overoptimism and the Performance of Entrepreneurial Firms. Management Science, 2006. 52(2): p. 173-186

30. Clarysse, B., M. Wright, and E. Van de Velde, Entrepreneurial Origin, Technological Knowledge, and the Growth of Spin-Off Companies. Journal of Management Studies, 2011. 48(6): p. 1420-1442.

31. Simeth, M. and M. Cincera, Corporate Science, Innovation, and Firm Value. Management Science, 2016. 62(7): p. 1970-1981.

32. Capaldo, A., D. Lavie, and A. Messeni Petruzzelli, Knowledge Maturity and the Scientific Value of Innovations:The Roles of Knowledge Distance and Adoption. Journal of Management, 2017. 43(2): p. 503-533.

33. Roach, M. and W.M. Cohen, Lens or Prism? Patent Citations as a Measure of Knowledge Flows from Public Research. Management Science, 2013. 59(2): p. 504-525.

34. Pitsakis, K., V. Souitaris, and N. Nicolaou, The Peripheral Halo Effect: Do Academic Spinoffs Influence Universities' Research Income? Journal of Management Studies, 2015. 52(3): p. 321-353.

35. Eesley, C., J.B. Li, and D. Yang, Does Institutional Change in Universities Influence High-Tech Entrepreneurship? Evidence from China's Project 985. Organization Science, 2016. 27(2): p. 446-461.

36. Holstein, J., K. Starkey, and M. Wright, Strategy and narrative in higher education. Strategic Organization, 2018. 16(1): p. 61-91.

37. Villani, E., E. Rasmussen, and R. Grimaldi, How intermediary organizations facilitate university-industry technology transfer: $A$ proximity approach. Technological Forecasting and Social Change, 2017. 114: p. 86-102.

38. Wright, M., et al., Knowledge Worker Mobility in Context: Pushing the Boundaries of Theory and Methods. Journal of Management Studies, 2018. 55(1): p. 1-26. 